\title{
Common Representation through UEML - Requirements and Approach
}

\author{
Roland Jochem \\ FhG-IPK, Germany, Roland.jochem@ipk.fhg.de
}

Abstract: At the current state of technology, we can state that Enterprise Modeling (EM) is now a reality in many large companies. Enterprise Engineering practices are developing and enterprises are under pressure to adopt engineering procedures based on models. However, interoperability between Enterprise modelling methods and also modelling tools is still very weak compared to real needs. Although both EM and EI are nearly not introduced in SMEs. They are only exposed when they take part in supply chains. In this case, they are told what to do and which tools they have to use. It is the author's opinion that these technologies would better penetrate any kind of enterprises if there were a standard interface in the form of a unified enterprise modelling language (UEML), which is based on a consensus on all modelling tools available on the market. This paper presents requirements and an approach to support common representation by a unified enterprise modelling language (UEML).

\section{INTRODUCTION}

The manufacturing world is in permanent change. Nowadays, it is moving from an economy of scale to an economy of scope under a global economy for mass customisation. For many companies around the world, staying in business means:

- To meet customer requirements,

- To reduce the time-to-market of their products, and

- To manufacture products at low cost with increased quality.

Thus, there is a need for better process management and for more integration within decentralised and modular individual enterprises (e.g. most 
discrete parts manufacturing companies) as well as among enterprises belonging to the same group or co-operating on collaborative projects (e.g. AIBUS consortium). Integration aims at providing quickly the right information at the right place at the right time under the right format throughout the enterprise, is therefore evolving (Vernadat, 1996). Enterprise Integration concerns:

- Efficient business process integration and co-ordination;

- Support to teamwork or computer supported collaborative work (CSCW) for concurrent design and engineering activities;

- Increased flexibility throughout the company;

- Total quality deployment to be introduced as early as possible in the product life cycle; and

- Collaboration of IT solutions, systems and people to face environment variability in a cost-effective way.

Among all these issues, process integration and co-ordination remains the most challenging problem because of its knowledge intensive nature.

Furthermore, it must be stressed that integration is a never-ending process. First, because it is a goal. Second, because the enterprise is in a permanent process of change. Its introduction must be carefully planned and documented by a master plan, and once started, procedures for continuous process improvements must be put in place (Jochem, 2001).

In a more general definition Integration consists of putting components together to form a synergistic whole. Different types of integration can be listed. They include in terms of Enterprises:

- Horizontal versus vertical integration

- Intra-enterprise versus inter-enterprise integration (Fig. 1)

The major problems currently faced by industry, which significantly limits the wide use of enterprise modelling, and engineering techniques concern Interoperability, Enterprise Integration, and Sharable Enterprise knowledge.

Interoperability: Business companies must use various tools from different vendors for obvious reasons of vendor independence and need for many kinds of functionality. Unfortunately, each vendor system comes as a stand-alone tool with its own proprietary language (or interface) forcing users to learn different languages and to model several times the same concepts due to non interoperable, closed systems.

Enterprise Integration: Any time two companies go for partnership or merging, they have to at least connect but in many cases tightly integrate their information systems and co-ordinate their business processes. Enterprise modelling is usually recognised as a prerequisite phase to Enterprise Integration to build a common vision or consensus in terms of business operations. 


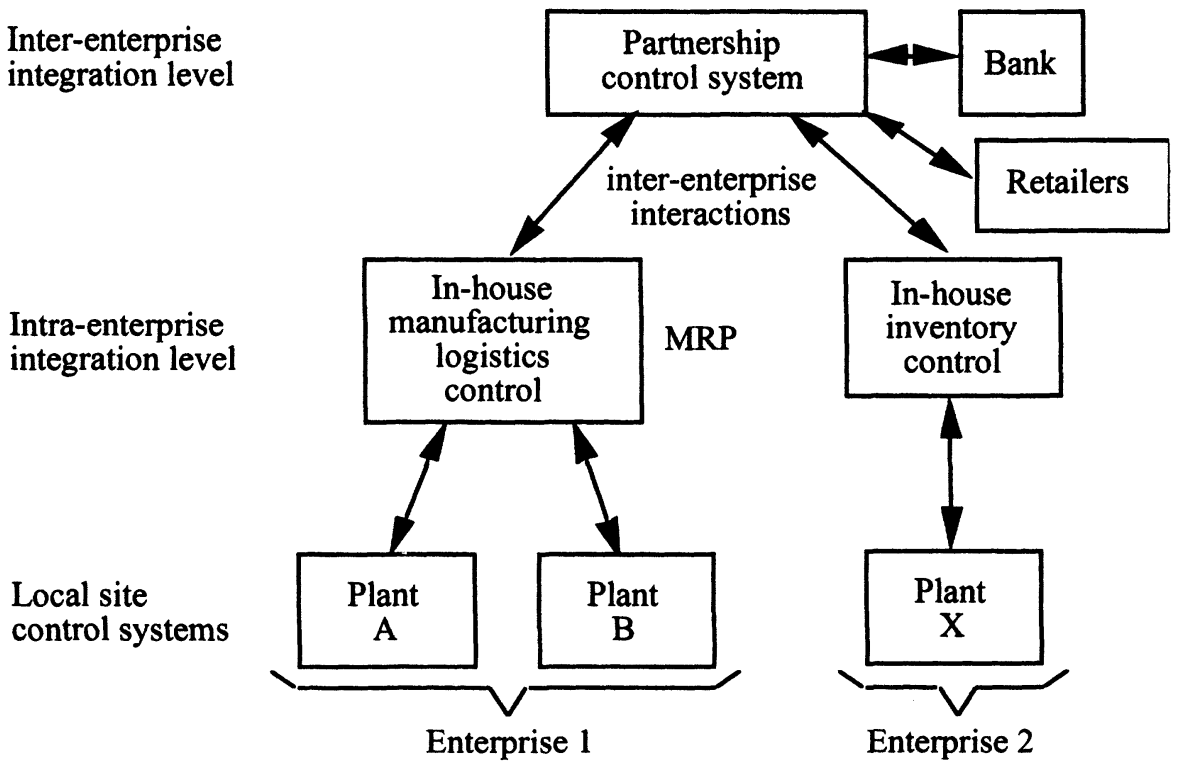

Figure 1: Inter-enterprise integration vs. intra-enterprise integration (Vernadat, 1999)

Sharable Enterprise Knowledge: Many business activities could be leveraged within single companies or within networks of enterprises (virtual enterprises, extended enterprises, large supply-chains) if they could share knowledge about the enterprises. This is not yet achievable at the level requested by industry because most tools encode fragmented knowledge in non-sharable way and do not access common repositories (IST-2001-34229, 2001).

This limitation has been recognised by standardisation bodies both at the European (CEN TC 310) and ISO (TC 184/SC5) levels. They have proposed guidelines for enterprise modelling/engineering (ENV 40003, 1993, ISO 15704, 1998) and modelling constructs (ENV 12204,1996).

Over the last decades, numerous efforts have been carried out in the field of Enterprise Modelling and Integration. With the application of modelling and integration principles in manufacturing (e.g. CAD/CAM integration, supply chain integration, CIM, Concurrent Engineering or just-in-time operations), significant improvements in terms of competitive advantages and industrial excellence are expected by means of better communication, coordination and co-operation between all levels and components of companies (IST-2001-34229, 2001).

Most major Projects (e.g. ESPRIT/CIMOSA, ICAM/IDEF, IPK/IEM, ESPRIT/CCE-CNMA, LUT/CIM-BIOSYS, PERA, GRAI/GIM, GERAM) 
have demonstrated the necessity of developing enterprise models to support analysis, design and management of the business processes that are executed in companies. These processes must be modelled from different points of view and at different levels for the purpose of building more integrated systems (stand-alone companies or networked enterprises). These ideas have even contributed to standardisation and unification efforts to harmonise concepts and terminology (CEN ENV 40003 and its reworked version, CEN ENV 12204 and its reworked version, ISO 15704, (1998), ISO/IEC 15414 (ODP), (2000), IFAC-IFIP (1997), OMG (2001), BPML (2001)).

Several commercial tools for enterprise engineering as well as process management are also being proposed based on these concepts (e.g. ARIS ToolSet, FirstSTEP, PrimeObjects, Bonapart, MOOGO, etc. in Mertins, 1998).

However, business users still face a variety of difficulties in their day-today work:

- Wide variety of available languages and technical approaches for modelling.

- Significant semantic gap between current different modelling languages.

- Poor interoperation capability of process modelling and management tools.

- Insufficient coverage by most languages of modelling views required by integrated engineering and management.

- Ignorance by most current enterprise modelling languages of aspects such as strategic goals, intentions, human roles and behaviour, knowhow and other so-called "soft issues".

- Diversity of graphical modelling representations (diagrammatic or semi-formal notations) and multitude of meanings for similar concepts (inconsistent semantics), which make difficult common understanding of enterprise models.

- Lack of a common standard language and exchange format make model exchange from one tool to another nearly impossible.

Because of this Tower of Babel situation, it becomes a necessity to define a unified language for universal use by business users as well as within the enterprise modelling community and which would address these problems (Vernadat, 1999). We therefore propose the development of such a language, called Unified Enterprise Modelling Language (UEML), by analogy with UML devoted to conceptual systems modelling. 


\section{OBJECTIVES AND APPROACH OF UEML}

The main objective of the UEML project is to define, to specify and to validate a set of core constructs and related services to support a Unified Language for Enterprise Modelling, named UEML, to serve as a basis for interoperability within a smart organisation or a network of enterprises (IST2001-34229, 2001).

This UEML will:

- Provide the business community with a common user interface to be used on top of most commercial enterprise modelling and workflow software tools,

- Provide a standardised mechanism for exchange of enterprise models among these tools,

- Support the implementation of open and evolutionary Enterprise Model Repositories to leverage enterprise knowledge engineering capability.

Taking into consideration previous work and existing tools, the main business objective of the UEML Project is to provide industry with a unified and expandable modelling language. The language, to be used on top of existing systems, will be defined as an open approach (i.e., an expandable set of core constructs with formal and graphical specifications) to describe the structure, behaviour and organisation of enterprises (be they related to service or goods industry). The language will be applicable to all sectors of industry and services, all enterprise dimensions and various kinds of enterprise processes (IST-2001-34229, 2001).

Therefore, it is important to mention that the objective of the project is $\underline{n o t}$ to develop a new language, which will replace the ones already in use, but rather to propose a language serving as a gateway (i.e. a mediating facility) between existing EM or workflow tools. UEML will be used as a facilitator within business applications of one enterprise or of a network of enterprises (extended enterprise).

Fig. 2 provides a global framework enabled by UEML and shows the expected result of the project (IST-2001-34229, 2001).

The global structure of the project will be based on two main elements:

UEML language for Modelling/Engineering Application: construct definition and specification, and demonstration that it can be implemented as a common user-interface on various commercial tools and used for model exchange.

Enterprise Knowledge Management based on a common Communication Layer and Repository services implementation (construct classes and type hierarchy definition, UEML API's, repository classes and services) demonstrating how an open, expandable, vendor independent infrastructure 
can be developed to implement UEML constructs and build shared Enterprise Knowledge Repositories to be accessed by various heterogeneous application systems

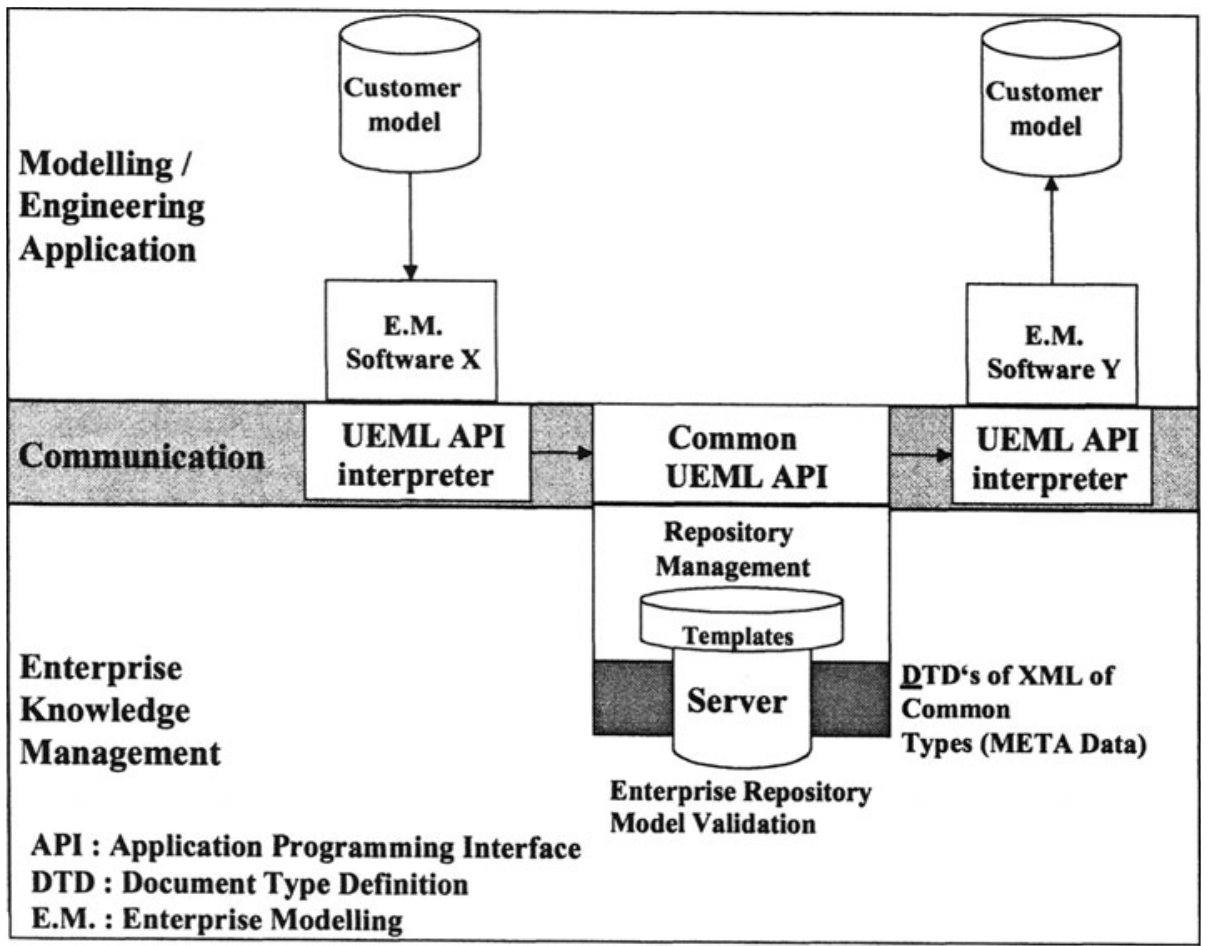

Figure 2: Expected results of the UEML Project

In the future, UEML should even become the basis for new system development. Assuming that the UEML language be unanimously accepted by the user community and strongly supported by standardisation organisations (especially, CEN and ISO), this work could significantly influence the Enterprise Modelling/Extended Enterprise software development industry. For instance, the UEML constructs could be the basis for the development of new generations of modelling and simulation tools to support enterprise analysis and engineering as well as inter-enterprise workflow management tools (ISI-2001-34229, 2001).

\section{RELEVANCE AND BENEFITS}

The relevance of UEML is clear because of its relevance to industrial companies as well as to consultants and software developers. First, a unified 
language that allows the development of exploitable models in an appropriate framework at different management levels of the company and at different levels of details would be welcome by the business user community.

Second, by learning UEML the business user will become able to interact with many tools without having to learn other dedicated languages, to move models from one tool to another more easily, and therefore be able to share or exchange models with his business partners. Third, tool developers will be provided with a clear and precise language definition to build a UEML interface for their proprietary tool. Last, UEML will bring some form of standardisation in the field of enterprise modelling by imposing a universal way of describing business processes and related elements, like UML currently does for conceptual modelling.

Furthermore, this common format and way of expressing enterprise models should make it easier to develop so-called reference models, i.e. partial, reusable models, which could be shared and commonly developed within a company or within a community of business partners (Mertins, 1999).

A "UEML" project has been implemented as an IST Thematic Network project (IST-2001-34229, 2001) which sets up a feasibility study to analyse the market potential of such a visual enterprise languages, to accurately define the specifications of a core of such a language, to validate it, to demonstrate and to disseminate the concepts.

The UEML Working Group will be composed with two kinds of memberships (IST-2001-34229, 2001):

- A core membership of the eight initial partners of the UEML project consortium and

- A network membership consisting of none-consortium organisations

The members of the UEML consortium are:

GRAISOFT (associated to the LAP/GRAI-University Bordeaux 1 and LABRI-University Bordeaux 1, France), INRIA (associated with CRANUniversity Henri Poincaré Nancy 1, France), COMPUTAS AS, Norway, CIMOSA Association, Germany, IPK/FhG Berlin, Germany, University of Torino, Italy, University of Namur, Belgium, University of Valencia, Spain.

All partners of this core membership have a strong background in the usage of one or more enterprise modelling languages and work in this research topic for a long time.

The UEML network will be established by the UEML consortium and will be composed of people from any kind of institution - industrial enterprise (end-users or provider of I.T. products), research, or standardisation 
bodies - who have an interest in the UEML core constructs definition and more generally in the complete UEML elaboration.

The UEML network will be supported by the UEML Working group for travelling expenses and also for assigned work.

Figure 3 below shows the relation between the two

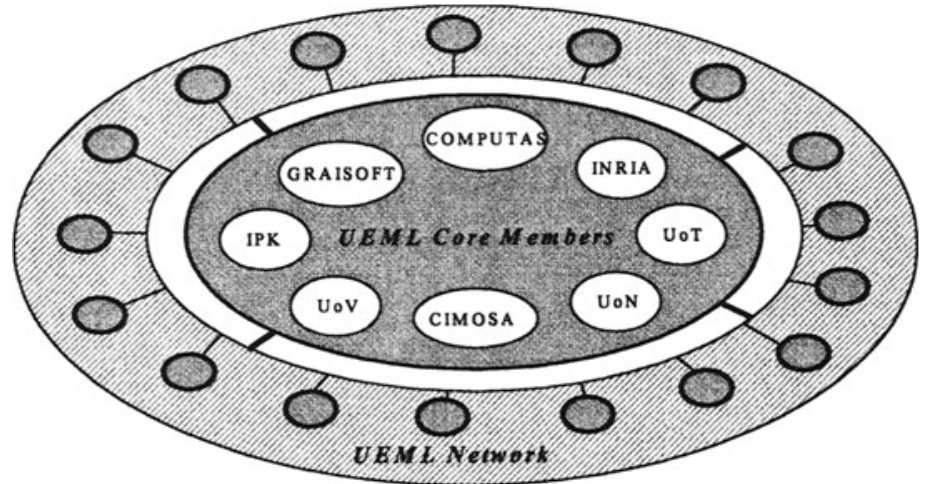

Figure 3: Relation between UEML Core Members and UEML groups.

The UEML network is an integral part of the project. The network has the goal to reach a common understanding and an improved consensus on enterprise modelling language constructs in the industry and academic community. It serves two purposes: 1) to disseminate general knowledge about UEML and project results and 2) to gather user requirements. Co-operation in the network is performed by the participation to core membership meetings, working groups, and information exchange via Web portals, electronic mail and distributed papers.

The members of the UEML network will be recruited from academia and various industry segments, from SMEs and large enterprises, from associations, European projects, standardisation bodies and industry initiatives. We intend to co-operate with the leading organisations in this field.

\section{CONCLUSION}

It must be well understood that it is not the intention of this project to reinvent the wheel, i.e. to invent yet another language, but rather to consolidate the accumulated knowledge and experience in the field of enterprise modelling by proposing a universal user-oriented language, or common tool interface, by generalising existing ones to, avoid the Tower of Babel situation currently prevailing and limiting the wide use of enterprise modelling technology.

The first step in that direction is the new established IST-Thematic Network Project "UEML" that will prepare the launching of a development project to define and implement a 'complete' UEML. 
The development of the UEML language will be accompanied by the development of Enterprise Ontologies (formal descriptions of entities as well as of their properties, relationships, constraints and behaviours). These Enterprise Ontologies will provide formal meta-models and micro-theories to enterprise modelling concepts.

In the future, this complete Unified Enterprise Modelling Language will allow to:

- Provide the business community with a common visual template based language to be used on top of most commercial enterprise modelling and workflow software tools,

- Provide standardised mechanisms for sharing knowledge models and exchanging enterprise models among projects, overcoming tool dependencies,

- Support the implementation of open and evolutionary enterprise model repositories to leverage enterprise knowledge engineering services and capabilities.

BPML, (2001), BPML - Business Process Modelling Language, BPMI.org.

ENV 12204, (1996), Constructs for Enterprise Modelling, CEN TC 310 WG1.

ENV 40003, (1993), Framework for Enterprise Modelling, CEN TC 310 WG1.

IFAC-IFIP Task Force, (1997), GERAM: Generalized Enterprise Reference Architecture and Methodology, Version 1.5, IFAC-IFIP Task Force on Architecture for Enterprise Integration.

ISO 15704, (1998), Requirements for Enterprise-Reference Architectures and Methodologies, TC 184 SC5t WG1.

ISO/IEC 10746, (1992), Information Technology - Open Distributed Processing - Basic Reference Model of Open Distributed Processing.

ISO/IEC 15414 (ODP), (2000), Information Technology - Open Distributed Processing Reference Model - Enterprise Viewpoint.

IST-2001-34229, (2001), Unified Enterprise Modelling Language (UEML). Description of Work. European Commission IST Project.

Jochem, R. (2001), Integrierte Unternehmensplanung auf der Basis von Unternehmensmodellen. Dissertation TU Berlin.

Mertins, K. Jochem, R. (1998), MOOGO. In: Bernus, P., Mertins, K.; Schmidt, G.: Handbook on Architectures of Information Systems, Springer-Verlag.

Mertins, K. Jochem, R. (1999), Quality-Oriented Design of Business Processes. Kluwer.

OMG, (2001), EDOC - Enterprise Distributed Object Computing

Vernadat, F.B. (1996), Enterprise Modeling and Integration: Principles and Applications, Chapman \& Hall.

Vernadat, F.B. (1999), Enterprise Modeling and Integration - Myth or Reality. In: Proceedings of CARS\&FOF 99 Conference, Aquas de Lindoia, Brazil. 